Chandrashekar K et al / IJRAP 4(1), Jan - Feb 2013

Review Article

www.ijrap.net

\title{
PHARMACOLOGICAL ACTIVITIES OF SPERMACOCE HISPIDA LINN: A REVIEW
}

Vinayak Meti ${ }^{1}$, Chandrashekar. $\mathrm{K}^{1 *}$, Shishir Mishra ${ }^{2}$

${ }^{1}$ Department of Pharmacology, Chettinad Hospital and Research Institute, Chettinad University, Chennai, Tamil Nadu, India

${ }^{2}$ Department of Pharmacology, SRM Medical College Hospital and Research Centre, SRM Nagar, Potheri, Kattankulathur, Tamil Nadu, India

Received on: 08/10/12 Revised on: 30/11/12 Accepted on: 11/12/12

*Corresponding author

E-mail: chandrashekarshkr61@gmail.com

DOI: $10.7897 / 2277-4343.04115$

Published by Moksha Publishing House. Website www.mokshaph.com

All rights reserved.

\section{ABSTRACT}

Spermacoce hispida Linn is one of the important plant belonging to the family of Rubiaceae and is commonly used herb in siddha medicine. This review supports all updated information on its chemical constituents, pharmacological activities, traditional uses and scientific approach. The plant extracts contains phytochemical constituents such as of saponins, tannins, phenolics, steroids, essential oils, flavonoids and terpenoids. The chemical entities of this plant have been used as an antidiabetic, anti-hypertensive, hepatoprotective, anti-inflammatory, antihyperlipidaemic, analgesic, antifungal, anticancer and antioxidant properties. This review is studied for the further development of various formulations for their traditional use and pharmacological activities.

Keywords: Spermacoce hispida, Rubiaceae, Antidiabetic, Hepatoprotective, Analgesic.

\section{INTRODUCTION}

For centuries, People have been using plants for their therapeutic values. Today 85000 plants have been documented for therapeutic use globally. The World Health Organization (WHO) estimates that almost $75 \%$ of world's population has therapeutic experience with herbal drugs $^{1}$. Among those medicinal plant, Spermacoce hispida Linn. is prominently used for treatment of various ailments and in the form of various preparations. It is one of the crude materials of Indian system of medicine. In India the indigenous system of medicine namely Ayurvedic, Siddha and Unani have been in existence for several centuries. Metals, minerals, gems and jewels are in the medicine since Vedic period. But they were used extensively during the post Buddhist era. Several Buddhist saints carried out research and composed works on metallic medicines. There has been a worldwide interest in scientifically validating the therapeutic efficacy of old traditional medicines. There are inherent problems in the scientific validation of clinically acclaimed effectiveness of plant products which are further attenuated by the lack of availability of suitable experimental and clinical models. However that should not discourage the development and quest for researching new drugs from these alternative systems of medicine.

Spermacoce hispida Linn has been extensively used in Siddha system of medicine for various conditions including decreasing the blood sugar levels. In traditional medicine, Spermacoce hispida is used to heal stomach ailments and also used as tonic and anti dandruff. The flowers have been applied to boils, eruptions, swellings and also regarded as an emetic and as a remedy for coughs and malaria. The plant under study has been used since ages by folk because of its rich medicinal values.
Spermacoce hispida Linn. Popularly known as "Nattaiccuri" in Tamil or "Shaggy button weed" in English, in Sanskrit it is known as Madanghanti and in Telugu it is called as Madan Granthi, and belongs to family of Rubiaceae, Subfamily is Rubioideae, and the genus- Spermacoce. The whole plant is used for medicinal properties; it is widely distributed in the Western Ghats of Kerala and in Maruthamalai forest, which is an extension of Western Ghats in Tamil $\mathrm{Nadu}^{2}$. As the seeds of plants as confection are cooling demulcent and given in diarrhoea and dysentery. Seeds have been recommended as a substitute for coffee. Seeds are crushed in to paste and taken orally to treat stomach problems ${ }^{3}$. The seed-extract of the plant has been used as a remedy for the treatment of internal injuries of nerves and kidney. It is suggested that it remove signs of old age, purify blood and improve vitality and has been used by the tribal's living in the forest regions in the Western Ghats of Kerala since ancient times. All the parts of the plant have an ethno medicinal importance 4 , It has been also reported that Spermacoce hispida is an effective natural drug for the treatment of hypertension and it has hepatoprotective, antiinflammatory and antioxidant properties. Recently, pharmacological studies have shown that Spermacoce hispida seeds exhibit antidiabetic properties and Antihyperlipidaemic activity in rats.

\section{Description}

Spermacoce hispida Linn. A weed is a procumbent, branched, hairy or rough herb 10 to 14 centimetres in length. The branches are greenish or purplish, ascending, stout, 4-angled (Figure 1). The leaves are ovate, speculate, or elliptic, 1 to 3.5 centimetres long, 0.8 to 1.7 centimetres wide, and pointed or rounded at the tip. The flowers (Figure 2) are 4 to 6 , and occur in a whorl in the axils of the leaves. The calyx-teeth are linear-lanceolate. The 
corolla is pale blue or white, and is 5 to 10 millimetres in length. The fruit is a hairy capsule about 5 millimetres in length. The seeds are oblong; granulate, opaque, usually variable, and 3 millimetres or less in length.

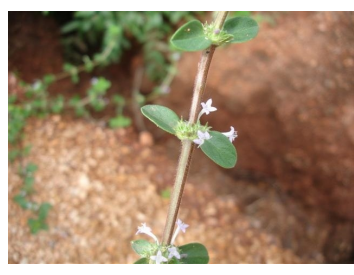

Figure 1

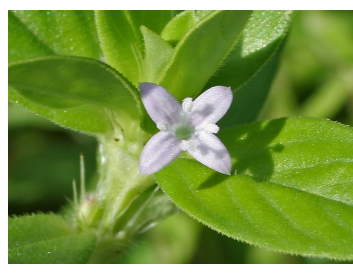

Figure 2

\section{Chemical Constituents}

Spermacoce hispida was one of the five plants which contained the maximum amount of flavonoids among 25 plants analyzed ${ }^{5}$.

The plant has been extensively studied for its phytochemical composition and a large number of active ingredients such as, Borreline, $\beta$-sitosterol (Figure 3), Ursolic acid (Figure 4) and Isorhmnatin. The preliminary Phytochemical investigation confirms the presence of Saponins, Tannins, Phenolics, Steroids, Essential oils, Flavonoids and Terpenoids ${ }^{6}$.

\section{$\beta$-sitosterol}

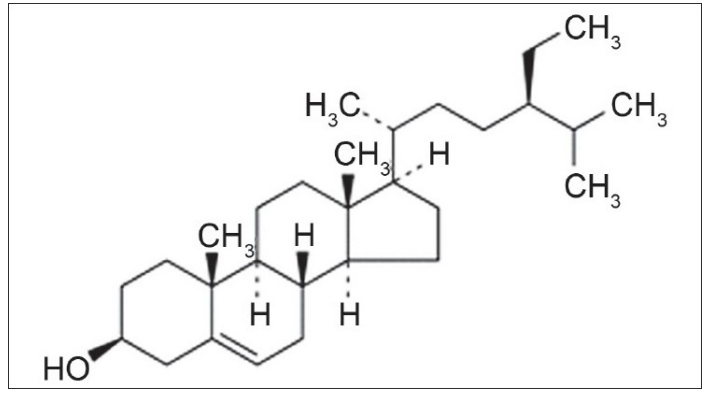

Figure 3: $\beta$-sitosterol

$\beta$-Sitosterol is one of several phytosterols (plant sterols) with chemical structures similar to that of cholesterol. It reduces blood levels of cholesterol, and is sometimes used in treating hypercholesterolemia. $\beta$-Sitosterol inhibits cholesterol absorption in the intestine. When the sterol is absorbed in the intestine, it is transported by lipoproteins and incorporated into the cellular membrane. Phytosterols and phytostanols both inhibit the uptake of dietary and biliary cholesterol, decreasing the levels of LDL and serum total cholesterol. Because the structure of $\beta$ sitosterol is very similar to that of cholesterol, $\beta$-sitosterol takes the place of dietary and biliary cholesterol in micelles produced in the intestinal lumen. This causes less cholesterol absorption in the body. One small study shows a positive effect on male hair loss in combination with Saw palmetto. In Europe, $\beta$-sitosterol is used in herbal therapy, especially for benign prostatic hyperplasia (BPH).

\section{Ursolic acid}

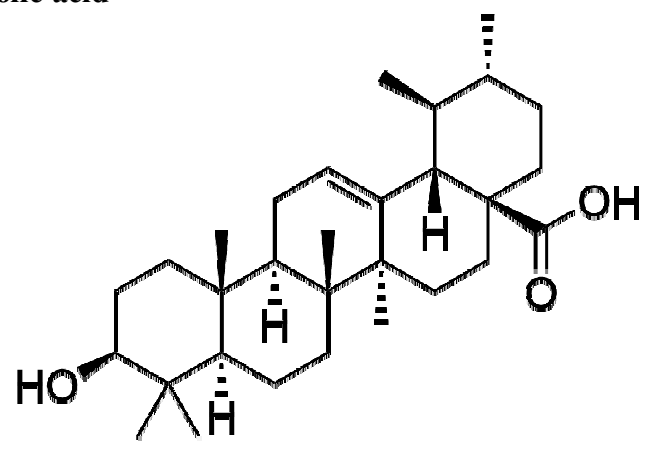

Figure 4: Ursolic acid

Ursolic acid is a pentacyclic triterpene acid, used in cosmetics, that is also capable of inhibiting various types of cancer cells by inhibiting the STAT3 activation pathway and human fibro sarcoma cells by reducing the expression of matrix metalloproteinase-9 by acting through the glucocorticoid receptor. It may also decrease proliferation of cancer cells and induce apoptosis. Ursolic acid is present in many plants, including apples, basil, bilberries, cranberries, elder flower, peppermint, rosemary, lavender, oregano, thyme, hawthorn, and prunes. Apple peels contain large quantities of ursolic acid and related compounds.

Ursolic acid can serve as a starting material for synthesis of more potent bioactive derivatives, such as antitumor agents. It has been found to reduce muscle atrophy and to stimulate muscle growth in mice. Ursolic acid has potential use as a cardio protective compound. Ursolic acid has been shown to increase the amount of muscle and brown fat and decrease obesity and associated conditions when added to diets fed to mice.

Traditional Uses

Spermacoce hispida Linn. is helpful in reducing the overweight or obesity, the leg yam prepared from this seeds is given twice daily to control bloody diarrhoea. The roots are dried and powdered and given along with cow's milk daily twice for conditions like urinary infections, oliguria etc and the choornam of the roots is taken daily for reducing the internal heat, venereal diseases etc. A decoction of the samoolam is helpful in treating head ache and recently it is found that this herb contains Calcium and Phosphorus in abundance hence administration of this drug in form of chooranam or kudineer (decoction) is recommended in conditions like bone diseases, fractures etc.

\section{PHARMACOLOGICAL ACTIVITIES Antioxidant activity}

Fractions rich in flavonoids obtained from Spermacoce hispida seeds were orally administered at three different doses of 20, 40 and $80 \mathrm{mg} / \mathrm{kg} \mathrm{BW}$ to HFD fed rats. The antioxidant activity of a flavonoid-rich fraction was measured both In vitro and In vivo. The flavonoid-rich fraction effectively scavenged DPPH and ABTS radicals In vitro. Further the results showed elevated activities of free radical-scavenging enzymes (SOD, CAT and GPx) and increased levels of non-enzymic antioxidants (GSH, vitamins $\mathrm{C}$ and $\mathrm{E}$ ). TBARS and lipid hydroperoxides 
decreased significantly in flavonoid-rich fraction treated rats compared to HFD control. Among the doses used, 40 $\mathrm{mg} / \mathrm{kg}$ BW dose showed maximum effect. Thus, the results indicate that a Spermacoce hispida seed flavonoidrich fraction possesses free radical scavenging and antioxidant activity both $\operatorname{In}$ vitro and $\operatorname{In} v i v o^{7,8}$.

\section{Anti-inflammatory Activity}

Inflammation can be defined as the response of the body to tissue injury involving neurological, vascular, humoral and cellular within the site of injury and depending upon the time course, it may be classified as acute, sub acute and chronic. In acute and sub acute inflammation both damage and repair are concurrently on and mononuclear white cells constitute a major population of the phagocytic cells in chronic inflammation.

Inflammation can be viewed as the response designed to minimize the effect of noxious substance at the site of injury by diluting, eliminating and by restricting its spread. Thus, it prepares ground for wound healing. The vascular response involves transient vasoconstriction followed by active vasodilatation in the area of injury. It involves all elements of the local vasculature leading to leakage of fluid with the composition similar to plasma containing fibrinogen and diluting the noxious substances. Subsequently formed elements of the blood adhere to one another and plug the capillaries ensuing local haemostasis. The cellular response is characterised by active passage of white cells through the vessel wall around the site of injury along with a few red cells. Initially the neutrophil polymorphs predominate followed by the monocytes, become phagocytic and are called as macrophages. The macrophages dispose dead and necrotic tissue and foreign bodies. They also attract and stimulate fibroblast proliferation, which is an essential feature of healing at the site of injury. Macrophages thus favour healing both directly, by influencing fibroblast and indirectly by preparing the site of healing. Therefore the cellular exudates appear to play a major role in the healing process.

The fibrin clot derived from fibrinogen of the fluid exudates surrounding the site of injury localizes the spread of inflammation. The fibrin clots aid phagocytosis and also forms the union between edges of severed tissue, contributing for the wound strength in the initial stages of healing. As the repair process sets in, the fibroblast movement is facilitated by these fibrin strands. The process of inflammation is initiated by number of chemical mediators like 5-HT and prostaglandins. These mediators may vary, depending upon the inflammation inciting agent e.g. prostaglandins participate predominantly in carageenan granuloma than in kaolin induced granuloma.

The anti-inflammatory activity of methanolic extract of Spermacoce hispida against carrageenan induced paw oedema shows that the extracts have significant effect on inflammation and markedly reduced the swelling. Indomethacin is a cycloxygenase inhibitor, the methanol extract has activity which is comparable to Indomethacin and can be said to inhibit the cycloxygenase enzyme but lipoxygenase inhibitors also possess significant antiinflammatory activity against carrageenan induced paw edema, so inhibition of carrageenan induced paw edema by the crude extract could also be due to its inhibitory activity on the lipoxygenase enzyme ${ }^{9}$.

\section{Analgesic activity}

Opioid analgesics are the mainstay drugs for moderate-tosevere pain associated with medical illness. Opioid analgesics can be classified as pure mu-agonists or agonist-antagonists based on their receptor interactions. The agonist-antagonist class can be subdivided into a mixed agonist-antagonist subclass and a partial agonist subclass. Because of their ceiling effect for analgesia and potential for reversing analgesia from pure agonists in physically-dependent patients, the agonist-antagonist drugs are not preferred for treating chronic pain.

Non-opioid analgesics include acetaminophen and nonsteroidal anti-inflammatory drugs (NSAIDS). They are usually used for mild-to-moderate pain. They have an additive effect when combined with opioids. There is substantial variability in the response of individual patients to different drugs. The selective COX-2 inhibitors (celecoxib, rofecoxib, valdecoxib, oncloxicam) have a more favorable GI safety profile than the nonselective COX-1 and COX-2 inhibitors. The nonselective drugs vary in toxicity. Drug selection should be influenced by drug-selective toxicities, prior experience, cost and convenience.

Adjuvant analgesics are drugs that have other primary indications but may be analgesic in specific circumstances. In the medically ill, adjuvant analgesics are more commonly used in the treatment of neuropathic pain. Drug selection should be guided by the risks associated with the therapy and the possibility of secondary benefits for symptoms other than pain. Sequential trials and dose titration are usually necessary. The appropriate use of adjuvant analgesics requires the clinician to know the approved indications, side effects, time-action relationship, pharmacokinetics, and specific guidelines for use in pain treatment.

Analgesic activity of ethanolic extract of Spermacoce hispida employing the acetic acid induced abdominal contractions and tail immersion models was studied. The plant extract showed significant analgesic activity when compared with standard drug aspirin and pentazocine. Spermacoce hispida elicits potential analgesic activity and may have both peripheral and central analgesic action ${ }^{10}$.

\section{Hypolipidemic activity}

Cholesterol is an important determinant of the structure and function of cell membranes, and plays an integral role in many neural functions that contribute to mood state and response to antidepressants. Statins are widely used in clinical practice to treat a variety of dyslipidemia and their clinical efficacy in controlling atherosclerosis, an outcome of prolonged hyperlipidemia is well established. Hypercholesterolemia is thus suggested to partly mediate age-related brain changes. In this context, cholesterollowering drugs, which block systemic cholesterol synthesis, may be a potential treatment option for a range of neurological disorders. Atherosclerotic endothelial dysfunction is one of the major causes of vascular diseases. Pathogenesis of atherosclerosis comprises a series of highly specific cellular and molecular responses that justify it, as an inflammatory disorder. 
Spermacoce hispida was selected to study antihyperlipidaemic activity against triton-WR-1339 induced hyperlipidaemia in rats. Hyperlipidaemia was induced in Wistar rats by intra-peritoneal (i.p) injections of Triton WR-1339 at a dose of $400 \mathrm{mg} / \mathrm{kg}$ body weight. Spermacoce hispida was administered orally at a dose of $200 \mathrm{mg} / \mathrm{kg}$ to triton WR-1339 induced hyperlipidaemic rats. After administration of Spermacoce hispida. It showed a significant decrease in the levels of cholesterol, phospholipids, triglycerides, LDL, VLDL and significant increase in the level of HDL in serum and liver tissues against triton induced hyperlipidaemic in rats. Therefore it effectively suppressed the triton induced hyperlipidemia in rats, suggesting the potential protective role in Coronary heart disease ${ }^{11}$.

\section{Antidiabetic Activity}

October 31, 1920 Dr. Banting conceives the idea of insulin after reading Moses Barron's 'The Relation of the Islets of Langerhans to Diabetes, For the next year, with the assistance of Best, Collip and Macleod, Dr. Banting continues his research using a variety of different extracts on de-pancreatized dogs. A de-pancreatized dog was successfully treated with insulin. W.H.O estimates that by 2025 total 300 million of the worldwide population will be affected by diabetes. It is reported that there are about 40 million diabetics in India. From Epidemic to Pandemic, there would be around 57.2 million diabetics by the year 2025 .

\section{Synthesis of Insulin - Produced in beta cells of the pancreatic islets Preproinsulin$$
\text { Proinsulin }
$$$$
\downarrow
$$$$
\text { Insulin- A chain (21 aminoacids) }
$$$$
\text { B chain (30 aminoacids) C peptide }
$$

Spermacoce hispida was investigated and reported to have hypoglycaemic activity in an animal model of diabetes upon subcutaneous administration. The oral administration of Spermacoce hispida in alloxan induced diabetic rats showed significant hypoglycemic effect. Recently, it was observed that chronic BQ use is associated with a higher risk of type 2 diabetes mellitus and metabolic syndrome ${ }^{7}$.

\section{Hepatoprotective activity}

Liver is one of the largest organs in human body and the chief site for intense metabolism and excretion. So it has a surprising role in the maintenance, performance and regulating homeostasis of the body. It is involved with almost all the biochemical pathways to growth, fight against disease, nutrient supply, energy provision and reproduction. The major functions of the liver are carbohydrate, protein and fat metabolism, detoxification, secretion of bile and storage of vitamin. Thus, a healthy liver is a crucial factor for overall health and well being. But it is continuously and variedly exposed to environmental toxins, and abused by poor drug habits and alcohol and prescribed and over-the-counter drug which can eventually lead to various liver ailments like hepatitis, cirrhosis and alcoholic liver disease. Thus liver diseases are some of the fatal disease in the world today. They pose a serious challenge to international public health. Modern medicines have little to offer for alleviation of hepatic diseases and it is chiefly the plant based preparations which are employed for their treatment of liver disorders but there is not much drug available for the treatment of liver disorders.

Therefore, many folk remedies from plant origin are tested for its potential antioxidant and hepatoprotective activity in experimental animal model. Carbon tetrachloride $\left(\mathrm{CCl}_{4}\right)$ induced hepatotoxicity model is widely used for the study of hepatoprotective effects of drugs and plant extracts.

The serum biochemical analysis results suggest that the use of ethanolic extract of Spermacoce hispida Linn exhibited significant protective effect from hepatic damage in $\mathrm{CCl}_{4}$ induced hepatotoxicity model. Histopathological studies revealed that concurrent administration of the extract with $\mathrm{CCl}_{4}$ exhibited protective effect on the liver, which further evidenced its hepatoprotective activity ${ }^{12}$.

Anti-Hypertensive activity

Blood Pressure $=$ Peripheral vascular Resistance $($ PVR $) \times$ Cardiac output

Hypertension $=$ Increased PVR $\times$ Increased Cardiac output Hypertension is the most common cardiovascular disease and is a major public health issue in developed as well as developing countries. Human essential hypertension is a complex, multifactorial, quantitative trait under polygenic control. Ethanolic extract of Spermacoce hispida has reduces the blood pressure in albino rats ${ }^{13}$.

\section{Antifungal Activity}

Fungal infections remain a significant cause of morbidity and mortality despite advances in medicine and the emergence of new antifungal agents. Since Ceratocystis paradoxa with multiple antibiotic resistance is increasing worldwide, it is of great importance to find effective treatments for these pathogens. Therefore, researchers are increasingly turning their attention to herbal medicine, looking for new leads to develop better drugs against microbial infections. To overcome the alarming problem of microbial resistance to antibiotics, the discovery of novel active compounds against new targets is a matter of urgency. The available antifungal drugs produce many adverse effects, show recurrence or lead to the development of resistance. The antifungal assay against the pathogen Ceratocystis paradoxa was determined by well diffusion method. The methanolic extracts of Spermacoce hispida leaves showed significant inhibitory activity ${ }^{14}$.

\section{Anticancer Activity}

Cancer is one of the most dangerous diseases in humans and presently there is a considerable scientific discovery of new anti cancer agents from natural products. The potential of using the natural products as anti cancer drugs was recognized in 1950's by U.S Natural Cancer Institute (NCI). Since 1950 major contributions have taken for the discovery of naturally occurring anti-cancer drugs. The plant Spermacoce hispida is tested for its anticancer activity. The anti-proliferative activity of Spermacoce hispida with cisplatin, anticancer drug was evaluated in human ovarian cancer cell line PA 1 was measured by MTT assay. This extract preferentially inhibited the growth of the cell lines in a dose-dependent manner. The 
result clearly indicates that the plant is rich in good source of antioxidants. The Spermacoce hispida plant fulfilled its promise to inhibit the proliferation of ovarian cancer cells. These results clearly indicate that Spermacoce hispida is effective against free radical mediated diseases ${ }^{15}$.

\section{CONCLUSION}

Spermacoce hispida is a one of the most important plant, which has most significant medicinal value. The survey of literature shown that Spermacoce hispida is an important source of many pharmacologically and medicinally important phyto-chemicals such as Borreline, $\beta$-sitosterol, Ursolic acid and Isorhmnatin. The plant has also been widely studied for their various pharmacological activities like antidiabetic, antihypertensive, antioxidant, analgesic, anticancer, hepatoprotective and antifungal. While Spermacoce hispida has been used successfully in siddha medicine for centuries, more clinical trials should be conducted to support its therapeutic use. This information may lead to further explorations of drugs developments programmes and group multiplication of the species for commercial and entrepreneur's developments in rural area of the country and world.

\section{REFERENCES}

1. Kasahara S and Hemini S. Medicinal Herb Index in Indonesia Bogor, Indonesia, P.T. Eisai Indonesia. 1998; 1:2.

2. Narayan DP, Kumar U. Agro's Dictionary of Medicinal Plants. Agrobios Publisher, Jodhpur, 2003.

3. Chellaiah M, Muniappan A, Nagappan R, Savarimuthu I. Medicinal plants used by traditional healers in Kancheepuram District of Tamil Nadu, India. Journal of Ethnobiology and Ethnomedicine.1999; 2:43

4. Orwa, Spermacoce Hispida botanical information. Agroforestry Database. 2009; 2

5. Sekar T, Francis K. A preliminary investigation of some Maruthamalai forest plants for phytochemical compounds. Biores.
Tech. $\quad 1999 ; \quad 70: 303-304 \quad$ http://dx.doi.org/10.1016/S0960$8524(99) 00021-8$

6. Khandelwal KR, Practical Pharmacognosy -Techniques and experiments, Nirali Prakasam, 17th Ed. 2007; 149-61

7. Kaviarasan K, Kalaiarasi P, Pugalendi V. Antioxidant efficacy of flavonoid rich fraction from Spermacoce hispida in hyperlipidemic rats. Journal of Applied Biomedicine. 2008; 6: 165-176.

8. Surveswaran S, Cai Y, Corke H, Sun M. Systematic evaluation of natural phenolic antioxidants from 133 Indian medicinal plants. Food Chem. 2007; 102:938-953 http://dx.doi.org /10.1016/j.foodchem.2006.06.033

9. Parthasarathy G. Evaluation of anti-inflammatory activity of methanolic extract of Spermacoce hispida Linn. J Pharm Res. 2010; 3:1516-7

10. Sundhararajan R, Ravichandiran V. Anti-nociceptive activity of ethanolic extract of Spermococe hispida L. Int. J.Res.Pharm. Sci. 2012; 3(1):173-175

11. Sivaelango G, Senthil Kumaran P. Antihyperlipidaemic Activity of Spermacoce Hispida Ethanolic Extract in Triton WR-1339 Induced Hyperlipidaemic Rats. Journal of Applied Pharmaceutical Science. 2012; 95-98

12. Karthikeyan M, Wawdhane SS, Kannan M, Rajasekar S. Hepatoprotective activity of ethanolic extract of spermacoce hispida.linn against carbon tetrachloride (ccl4) induced hepatotoxicity on albino wistar rats. International Journal of Pharma Research and Development. 2011; 2 (11): 45-52

13. Arnold N, Schmidt J. Plant. Constituents of Traditional Medicinal Plants. 2nd ed. scientific report, Leibniz Institute of Plant Biochemistry, Leibniz. 2004; p. 23-24.

14. Mahalingam RV, Ambikapathy, Panneerselvam A. Studies on Antifungal Activities of Some Medicinal Plants Against Ceratocystis Paradoxa Causing Pineapple Disease. World Journal of Science and Technology 2011; 1(7): 10-13

15. Rathi MA, Meenakshi P, Guru Kumar D, Arul Raj C, Sunitha M and Gopalakrishnan VK. Leaves of Spermacoce hispida as a Novel Cancer Therapeutic - An in Vitro Study. Research Journal of Pharmacy and Technology. 2011; 4(08): 1288-91

Cite this article as:

Vinayak Meti, Chandrashekar. K, Shishir Mishra. Pharmacological activities of Spermacoce hispida linn: A review. Int. J. Res. Ayur. Pharm. 2013; 4(1): 18-22 